Supporting Information for

\title{
Reductive adsorption of atmospheric oxidized mercury on ice: Insights from density functional calculations
}

\author{
Yoo Soo Yi ${ }^{1, *}$, Yeongcheol Han ${ }^{1, *}$, Soon Do Hur ${ }^{1}$
}

\section{AUTHOR INFORMATION}

\section{Corresponding Author}

Yoo Soo Yi - Division of Glacial Environment Research, Korea Polar Research Institute, Incheon 21990, Korea; orcid.org/0000-0002-5479-0357;

Email: yys2064@,kopri.re.kr

Yeongcheol Han - Division of Glacial Environment Research, Korea Polar Research Institute, Incheon 21990, Korea; https://orcid.org/0000-0002-1729-7870;

Email: yhan@kopri.re.kr

\section{Coauthor}

Soon Do Hur - Division of Glacial Environment Research, Korea Polar Research Institute, Incheon 21990, Korea

Email: sdhur@kopri.re.kr 


\section{SI1. Cleaved surface structures of selected adsorbents}

Figure S1 presents the cleaved surface structures of ice-Ih, halite, and illite used for determining the binding energies $\left(E_{\mathrm{B}}\right)$ of atmospheric $\mathrm{Hg}$ on the selected adsorbents. The potential adsorption sites are illustrated in Figure S2. The uppermost $\mathrm{d}(\mathrm{H})$ and $\mathrm{d}(\mathrm{O})$ atoms can act as reactive adsorption sites for the atmospheric $\mathrm{Hg}^{\mathrm{II}}$ molecules via attractive intermolecular interactions; for example, (1) $3 \mathrm{~d}(\mathrm{H})^{[+]}-\mathrm{X}^{[-]} \ldots \mathrm{Hg} \cdots \mathrm{X}^{[-]}-3 \mathrm{~d}(\mathrm{H})^{[+]}$on ice-Ih ${ }^{1}$ (Fig. 1b), (2) $\mathrm{Cl}^{[-]}-\mathrm{Hg}^{[+]} \mathrm{O}$ on halite (Fig. 1j), and (3) $2 \mathrm{~K}^{[+]} \ldots \mathrm{X}^{[-]} \mathrm{HgX}^{[-]} \ldots 2 \mathrm{~K}^{[+]}$and $\mathrm{X}_{2}{ }^{[-]} \mathrm{Hg}^{[+]} \ldots \mathrm{O}^{[-]}$at the siloxane ring on illite (Figs. $1 \mathrm{~m}$ and $1 \mathrm{n}$ ). The structural information of these cleaved surface structures and their bulk crystals are summarized in Table S1.
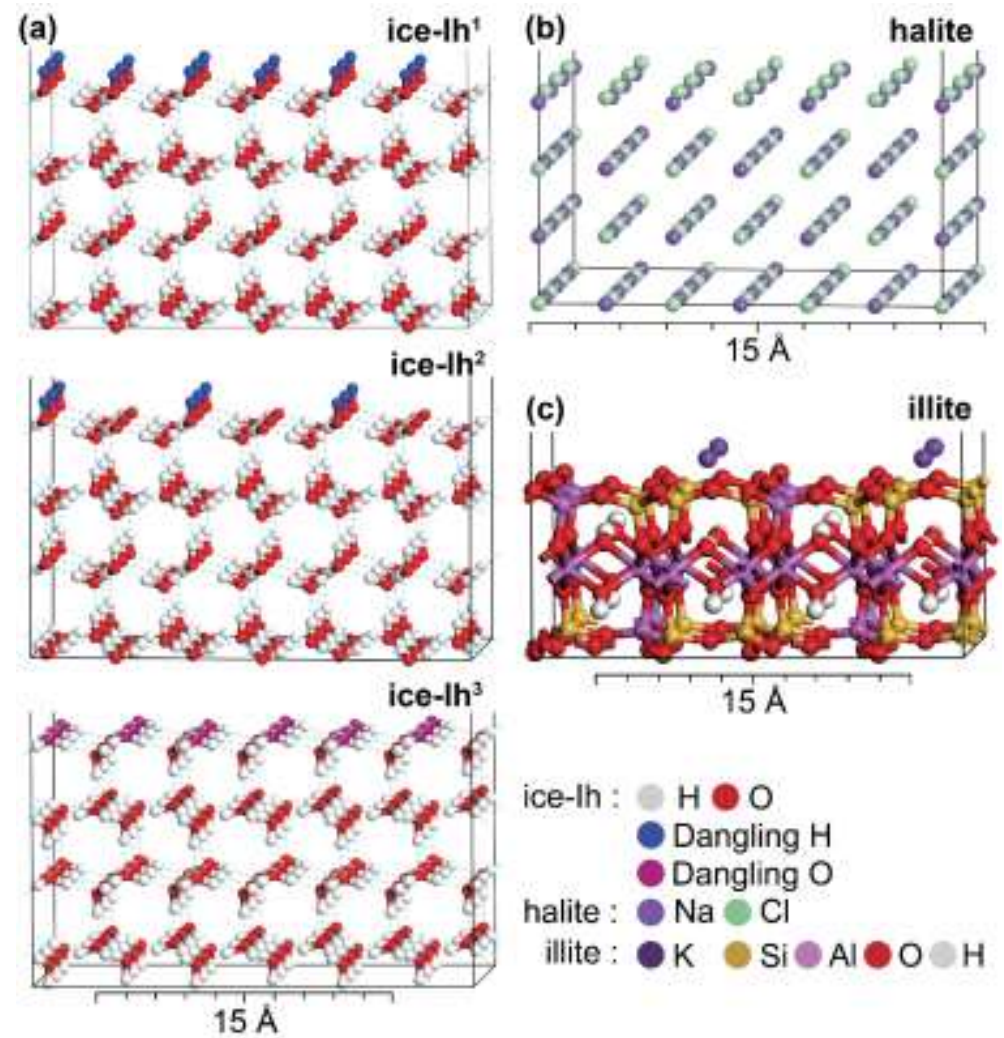

Figure S1. Cleaved surface structures of the selected adsorbents: (a) the ice-Ih (0001) surfaces decorated with dangling $\mathrm{H}, \mathrm{d}(\mathrm{H})$, atoms (ice- $\mathrm{Ih}^{1}$ ) and with proton defects (ice- $\mathrm{Ih}^{2}$ ) and the ice-Ih $(000 \overline{1})$ surface decorated with dangling $\mathrm{O}, \mathrm{d}(\mathrm{O})$, atoms $\left(\mathrm{ice}-\mathrm{Ih}^{3}\right)$. (b) The halite $(001)$ surface. (c) The illite (001) surface. 
(a)
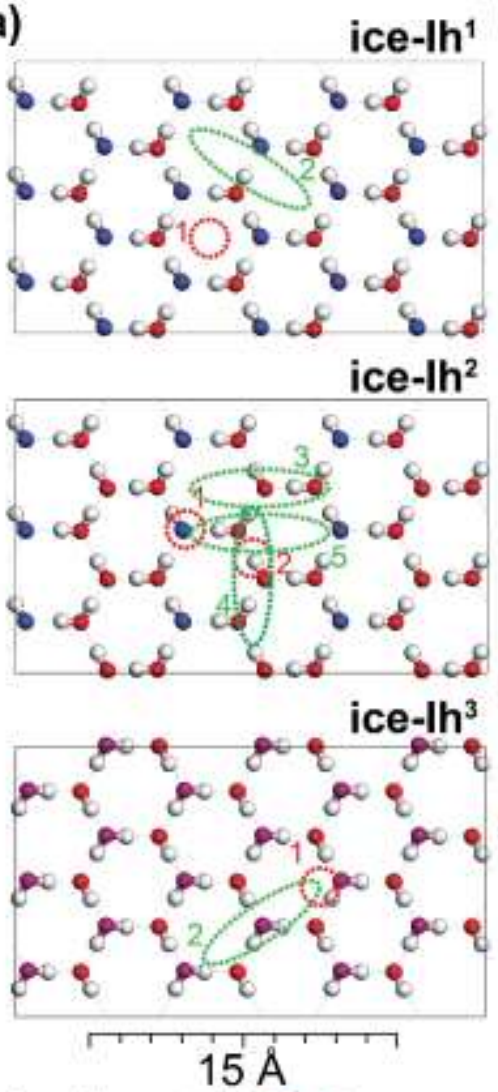

ice-lh :
$\mathrm{HOO}$

Dangling $\mathrm{H}$

Dangling $\mathrm{O}$ (b)

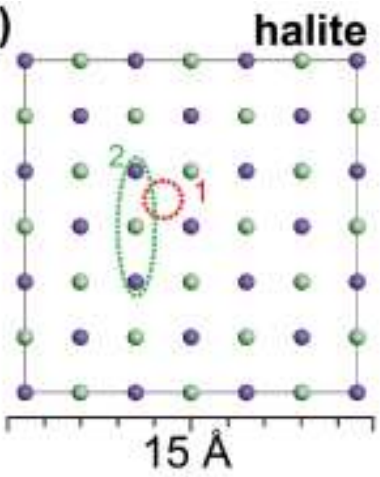

(c)

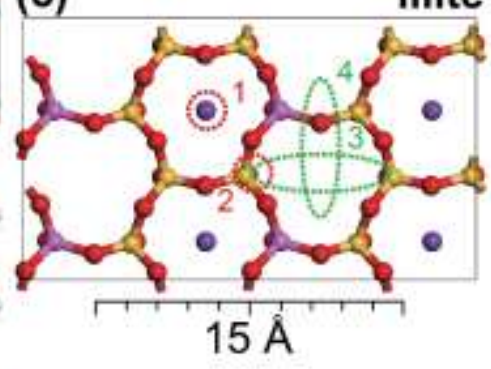

halite : $\bigcirc \mathrm{Na} \odot \mathrm{Cl}$

illite : $O \mathrm{~K} \odot \mathrm{Si}$

$\mathrm{Al} \odot \mathrm{O}$

Figure S2. Potential adsorption sites for atmospheric $\mathrm{Hg}$ on the selected adsorbents. (a) The ice-Ih (0001) and (0001) surfaces, (b) the halite (001) surface, and (c) the illite (001) surface. The red and green dashed circles (or ovals) indicate the sites for $\mathrm{Hg}^{\mathrm{II}}$ compounds that adhere to the surface vertically and horizontally, respectively. Only the atoms of the uppermost bilayer are presented for ease of viewing. 
Table S1. Structural information of ice-Ih, halite, and illite (lattice parameters, cleavage directions, and sizes of cleaved surfaces).

\begin{tabular}{cccc}
\hline Adsorbents & Ice-Ih & Halite & Illite \\
\hline $\begin{array}{c}\text { System } \\
\text { Space group }\end{array}$ & $\begin{array}{c}\text { Monoclinic } \\
(9) \mathrm{CC}\end{array}$ & $\begin{array}{c}\text { Cubic } \\
(225) \mathrm{FM} \overline{3} \mathrm{M}\end{array}$ & $\begin{array}{c}\text { Monoclinic } \\
(12) \mathrm{C} 2 / \mathrm{M}\end{array}$ \\
$\begin{array}{c}\text { Lattice parameters of the unit cell } \\
\mathrm{a}(\AA)\end{array}$ & 7.8219 & 5.6400 & 5.2021 \\
$\mathrm{~b}(\AA)$ & 8.6299 & 5.6400 & 8.9797 \\
$\mathrm{c}(\AA)$ & 8.6299 & 5.6400 & 10.2260 \\
$\alpha\left({ }^{\circ}\right)$ & 90.00 & 90.00 & 90.00 \\
$\beta\left(^{\circ}\right)$ & 121.55 & 90.00 & 95.76 \\
$\gamma\left({ }^{\circ}\right)$ & 90.00 & 90.00 & 90.00 \\
$(h k l)$ & & & \\
Direction of the cleavage plane & $(0001),(000 \overline{1})$ & $(001)$ & $(001)$ \\
Sizes of the cleaved surfaces & & & \\
$\mathrm{a}(\AA)$ & 13.1921 & 17.9322 & 10.4042 \\
$\mathrm{~b}(\AA)$ & 22.8061 & 10.8498 & 17.9594 \\
$\mathrm{c}(\AA)$ & 52.6997 & 50.1536 & 48.4581 \\
Surface area $\left(\AA^{2}\right)$ & 300.8610 & 194.5606 & 186.8532 \\
Layer thickness $(\AA)$ & 13.0837 & 10.1882 & 7.9319 \\
Vacuum thickness $(\AA)$ & 39.6160 & 39.9655 & 40.5262 \\
Number of atoms & $414-432$ & 140 & $160-168$ \\
\hline & & & \\
\hline
\end{tabular}




\section{SI2. Details for electronic structure calculations}

In the current study, the calculation parameters were referred from previous studies and adjusted in the context of calculation efficiency: the surface adsorption behavior, ${ }^{1-3}$ the metal intercalation tendency into clay minerals, ${ }^{4-5}$ the electronic structure of high-pressure minerals, ${ }^{6-11}$ and the electronic transition spectroscopy (X-ray Raman scattering, X-ray absorption, and optical properties, etc.). ${ }^{6-7,10-11}$

As summarized in the manuscript, the adsorption behaviors of atmospheric $\mathrm{Hg}$ on ice were explored via DFT calculations with following conditions: the ultrasoft pseudopotential, the PerdewBurke-Ernzerhof (PBE) exchange-correlation functional with Tkatchenko-Scheffler (TS) dispersion correction, the $400 \mathrm{eV}$ of cut-off energy, and the $\Gamma$ point Brillouin zone sampling. ${ }^{12-14}$

When using the non-localized plane-wave basis sets (e.g., WIEN2 $\mathrm{k}^{15-16}$ and CASTEP ${ }^{12}$ ), the accuracy is determined primarily from the cutoff energy and the number of irreducible $k$ points (i.e., the density of Monkhorst-Pack grid). For the ultrasoft pseudopotential method, the $\sim 400 \mathrm{eV}$ of cutoff energy can provide sufficiently converged total energy values for simple non-metallic systems (see details in the user guide of CASTEP and the benchmark results for the similar system in a previous study ${ }^{17}$ ). For the number of $k$ points, it has been known that the large supercell structure requires a fewer number of $k$ points. ${ }^{12,16}$ Thus, the $\Gamma$ point sampling would be sufficient for the surface structure models used here (containing $\sim 140-400$ atoms with the large vacuum space $\sim 40 \AA$ ). We also confirmed that the calculated electronic transition spectra for simple oxides were sufficiently converged with the small number of irreducible $k$ points $(\sim 1-8)$, so as to analyze the experimental results. In contrast, the phonon calculations ${ }^{4,9,18-19}$ and the electronic structure calculations for metallic system ${ }^{12,15,20-21}$ usually require more denser MP grid (e.g., $12 \times 12 \times 12$ ); then, the convergences should be verified even for the large supercell structures.

Note that, when performing DFT calculations, the accuracy of calculation is significantly affected by the choice of exchange-correlation functional. In the current study, we used the most used exchange-correlation functional, i.e., the generalized gradient approximation based PBE. ${ }^{12,15,20-22}$ The PBE functional has been used in many previous studies to investigate various minerals, ${ }^{1,23}$ and also provided reliable results for the $\mathrm{H}_{2} \mathrm{O}$-based system such as water and ice. ${ }^{24}$ It has been known that revised-PBE method can provide more accurate intra-molecular vibrations (i.e., the $\mathrm{H}_{2} \mathrm{O}$ vibrational modes), but it tends to overestimate O-H bond lengths. ${ }^{18-19,25}$ Sometimes, ice-specific 
potential functions are used, but they are usually not for general use including other elements. ${ }^{26-27}$ In addition, for molecular crystals like ice-Ih, the long-range dispersion interactions such as the van der Waals interactions and hydrogen bonds, are also crucial. ${ }^{24}$ Thus, in this study, we applied the TS dispersion correction scheme. ${ }^{14}$ Comparison between the PBE-TS method used here and higher level of post-Hartree-Fock methods is discussed in the manuscript (see Results and Discussion for Figs. 1 and 2).

The tolerance of our results using the calculated parameters adjusted for computational efficiency was verified by comparison with experimental or highly accurate computational results. In Table S5, we compare the calculated $E_{\mathrm{B}}$ for the $\mathrm{HgBr}_{2}$ molecule with the results of highly accurate calculations based on the PBE0 method with aug-cc-pVTZ-PP RECP basis sets. ${ }^{28}$ The previous study revealed the reaction pathways of $\mathrm{HgBr}_{2}$ dissociation: (in gas phase) $\sim 3.17 \mathrm{eV}$ for $\mathrm{HgBr}_{2} \rightarrow \mathrm{Br}+$ $\mathrm{HgBr}$ and $\sim 0.93 \mathrm{eV}$ for $\mathrm{Br}+\mathrm{HgBr} \rightarrow \mathrm{Br}+\mathrm{Hg}+\mathrm{Br}$ (see Ref. for details ${ }^{28}$ ). In our study, $E_{\mathrm{B}}$ was calculated with the non-relativistic Schrödinger approach by using the ultrasoft pseudopotential. Because the ultrasoft pseudopotential represents the electronic orbitals with pseudized valence electrons well-tuned for determining relatively simple interactions, ${ }^{29}$ the calculated $E_{\mathrm{B}}$ were comparable to the previous results, with differences of $\sim 1.08-8.83 \%$ (see Table S5): $\sim 3.45 \mathrm{eV}$ for $\mathrm{HgBr}_{2} \rightarrow \mathrm{Br}+\mathrm{HgBr}$ and $\sim 0.94 \mathrm{eV}$ for $\mathrm{Br}+\mathrm{HgBr} \rightarrow \mathrm{Br}+\mathrm{Hg}+\mathrm{Br}$. This comparison shows that our calculations can provide sufficiently reliable results for examining the adsorption behaviors of atmospheric $\mathrm{Hg}$ on ice surfaces. For the intermolecular interactions stemming from $\mathrm{H}_{2} \mathrm{O}$ molecules, a previous study reported that the PBE-TS method overestimates those interactions (e.g., binding/sublimation energy of $\mathrm{H}_{2} \mathrm{O}$ ) by $\sim 10-20 \%$ compared to highly accurate $\operatorname{CCSD}(\mathrm{T})$ calculations (see Ref. for the benchmark results for $\mathrm{H}_{2} \mathrm{O}$-molecular systems from relatively small molecular clusters to ice-Ih). ${ }^{24}$

We carried out more precise calculations with higher-order parameters (see details in Table $\mathrm{S} 5$ ), but there were no appreciable improvements. The $E_{\mathrm{B}}$ values calculated with the scalar (or full) relativistic correction resulted in differences of $\sim 1.08-9.15 \%$ (or $\sim 1.08-7.57 \%$ ) compared to the results of highly accurate calculations. We also examined the molecular dissociation energy of $\mathrm{HgO}$, $2.46-2.28 \mathrm{eV}$ (Table S5). The dissociation energy of $\mathrm{HgO}$ determined by using the full relativistic DFT/B3LYP calculation in a previous study was $\sim 2.1 \mathrm{eV}$; the other theoretical and experimental results were in the range of $\sim 1.8-4.0 \mathrm{eV}$; see Ref. for details. ${ }^{30}$ Note that, the on-the-fly generation pseudopotential with the projector-augmented plane waves (PAW) method, used in CASTEP, is 
known to be as accurate as the full-potential (all-electron) calculations via WIEN2k. ${ }^{12,31}$ Then, this limited accuracy in the $E_{\mathrm{B}}$ calculations, compared to the post-Hartree-Fock methods (e.g., MP2, CASPT, and $\mathrm{CCSD}^{32-33}$ ) or other hybrid methods (e.g., PBE0 ${ }^{24,33}$ ), may be due to the intrinsic approximations in DFT-based methods. The relativistic effects on $\mathrm{Hg}$ compounds will be discussed below.

Table S2. Calculated binding energies $\left(E_{\mathrm{B}}\right)$ of $\mathrm{HgBr}_{2}$ and $\mathrm{HgO}$ are compared with the results of previous study. Differences with respect to corresponding values are presented.

\begin{tabular}{ccccc}
\hline $\left.\boldsymbol{E}_{\mathbf{B}} \mathbf{( e V}\right)$ & Previous & ${ }^{\text {(1) }} \mathbf{U P}$ & ${ }^{\text {(2) }}$ OTF-sRel & ${ }^{\text {(3) }}$ NP-sRel-SO \\
\hline $\mathrm{HgBr}_{2} \rightarrow \mathrm{Br} \cdots \mathrm{HgBr}$ & ${ }^{(4)}-3.17$ & $-3.45(8.83 \%)$ & $-3.46(9.15 \%)$ & $-3.41(7.57 \%)$ \\
$\mathrm{Br} \cdots \mathrm{HgBr} \rightarrow \mathrm{Br} \cdots \mathrm{Hg} \cdots \mathrm{Br}$ & ${ }^{(4)}-0.93$ & $-0.94(1.08 \%)$ & $-0.94(1.08 \%)$ & $-0.94(1.08 \%)$ \\
$\mathrm{HgO} \rightarrow \mathrm{Hg}+\mathrm{O}$ & $(5)-2.10$ & $-2.28(8.57 \%)$ & $-2.46(17.14 \%)$ & \\
\hline
\end{tabular}

(1) Calculated $E_{\mathrm{B}}$ using the ultrasoft pseudopotential (see details above); the PBE-TS method, the $400 \mathrm{eV}$ of cutoff energy, and the $\Gamma$ point sampling.

(2) Calculated $E_{\mathrm{B}}$ using the norm-conserving on-the-fly pseudopotential with the first-order relativistic correction (i.e., the scalar relativistic correction); the $1000 \mathrm{eV}$ of cutoff energy, and the $\Gamma$ point sampling.

${ }^{(3)}$ Calculated $E_{\mathrm{B}}$ using the norm-conserving pseudopotential with the full relativistic correction (i.e., the scalar relativistic correction + the spin-orbit coupling); the $1000 \mathrm{eV}$ of cutoff energy, and the $\Gamma$ point sampling.

(4) Theoretically calculated $E_{\mathrm{B}}$ for $\mathrm{HgBr}_{2}$ gas phase, via Gaussian 03 with aug-cc-pVTZ-PP RECP basis sets (i.e., including small-core relativistic effective core potential ${ }^{34-35}$ ) and PBE0 functional (see the previous study for details). ${ }^{28}$

${ }^{(5)}$ Theoretically calculated $E_{\mathrm{B}}$ for $\mathrm{HgO}$ via the full relativistic DFT/B3LYP calculation. ${ }^{30}$ 


\section{SI3. Calculated $E_{B}$ values}

The calculated binding energy $\left(E_{\mathrm{B}}\right)$ for atmospheric $\mathrm{Hg}$ adsorbed on each potential adsorption site and the energy differences associated with the adsorption-induced structural changes of atmospheric $\mathrm{Hg}\left(\Delta E_{\mathrm{Hg}}=E_{\mathrm{Hg}}-E_{\mathrm{Hg}}^{0}\right)$ and surfaces $\left(\Delta E_{\text {Surf }}=E_{\text {Surf }}-E_{\text {Surf }}^{0}\right.$ ), are listed in Table S3 (see Fig. 2 for the trend of $E_{\mathrm{B}}$ ). The $E_{\mathrm{B}}$ of $\mathrm{Hg}, \mathrm{HgCl}$, and $\mathrm{HgBr}$, formed through dissociative adsorption of $\mathrm{Hg}^{\mathrm{II}}$ on ice- $\mathrm{Ih}^{1}$ and ice- $\mathrm{Ih}^{2}$ surfaces, are summarized in Table $\mathrm{S} 4$ (see also Fig. 2 for details). The precision of calculated results in Table S3 would be in the order of $\sim 0.1 \mathrm{eV}$ (see SI4 for details). Despite that, most $\Delta E_{\text {Surf }}$ of ice- $\mathrm{Ih}^{2}$ are noticeably $<0 \mathrm{eV}$ (e.g., $\Delta E_{\text {Surf }}<-0.2 \mathrm{eV}$ for $\mathrm{HgClBr}$ at site 03; see Fig. 1d). This is because the ice- $\mathrm{Ih}^{2}$ surface is metastable with the manipulated $\mathrm{d}(\mathrm{O})$ sites; the uppermost $\mathrm{d}(\mathrm{H})$ atoms can shift toward nearby $\mathrm{d}(\mathrm{O})$ atoms during the adsorption-induced structural changes. Similar trend can be observed in the results of illite, where some of K atoms on the siloxane ring are removed, making them reactive for positively charged $\mathrm{Hg}$ atom (around sites 03 and 04) (see Ref. for the uppermost $\mathrm{K}$ defects on illite $^{36}$ ).

Table S3. Calculated binding energy $\left(E_{\mathrm{B}} ; \mathrm{eV}\right)$ for the atmospheric $\mathrm{Hg}$ species adsorbed on the selected adsorbents and the energy differences associated with the adsorption-induced structural changes of atmospheric $\mathrm{Hg}\left(\Delta E_{\mathrm{Hg}}=E_{\mathrm{Hg}}-E^{0}{ }_{\mathrm{Hg}}\right)$ and surfaces $\left(\Delta E_{\text {Surf }}=E_{\text {Surf }}-E^{0}\right.$ Surf $)$; see Fig. 2 for details.

\begin{tabular}{|c|c|c|c|}
\hline Adsorption sites & (1) $E_{\mathrm{B}}$ & (2) $\Delta E_{\mathrm{Hg}}$ & (3) $\Delta E_{\text {Surf }}$ \\
\hline \multicolumn{4}{|l|}{ Ice--Ih $^{1}$} \\
\hline $\mathrm{HgO}$ at site 01 & -7.6604 & 1.5279 & 1.1420 \\
\hline $\mathrm{HgO}$ at site 02 & -7.7001 & 1.4680 & 1.1852 \\
\hline $\mathrm{HgBr}_{2}$ at site 01 & -1.7213 & 2.6046 & 0.3256 \\
\hline $\mathrm{HgBr}_{2}$ at site 02 & -5.0205 & 4.0317 & 0.5926 \\
\hline $\mathrm{HgCl}_{2}$ at site 01 & -1.8149 & 3.0086 & 0.4191 \\
\hline $\mathrm{HgCl}_{2}$ at site 02 & -5.2501 & 4.6544 & 0.7463 \\
\hline $\mathrm{Hg}^{0}$ at site 01 & -0.2042 & 0.0000 & -0.0586 \\
\hline $\mathrm{HgClBr}$ at site 01 & -1.8637 & 2.8776 & 0.4147 \\
\hline (4) $\mathrm{HgClBr}(\mathrm{R})$ at site 01 & -1.6469 & 2.7981 & 0.3295 \\
\hline $\mathrm{HgClBr}$ at site 02 & -5.0604 & 4.3270 & 0.6686 \\
\hline $\mathrm{HgClBr}(\mathrm{R})$ at site 02 & -5.1203 & 4.3363 & 0.6535 \\
\hline \multicolumn{4}{|l|}{ Ice--Ih ${ }^{2}$} \\
\hline $\mathrm{HgO}$ at site 01 & -0.8169 & -0.0370 & -0.2628 \\
\hline $\mathrm{HgO}$ at site 02 & -4.9529 & 1.1406 & 0.2228 \\
\hline $\mathrm{HgO}$ at site 03 & -3.2632 & -0.0470 & -0.1283 \\
\hline $\mathrm{HgO}$ at site 04 & -3.3581 & -0.0477 & -0.0766 \\
\hline $\mathrm{HgBr}_{2}$ at site 01 & -0.2723 & -0.0056 & -0.1730 \\
\hline $\mathrm{HgBr}_{2}$ at site 02 & -0.5668 & 0.0010 & -0.2933 \\
\hline
\end{tabular}




\begin{tabular}{|c|c|c|c|}
\hline $\mathrm{HgBr}_{2}$ at site 03 & -1.3542 & 0.2446 & -0.2222 \\
\hline $\mathrm{HgBr}_{2}$ at site 04 & -4.2849 & 2.6614 & -0.0660 \\
\hline $\mathrm{HgBr}_{2}$ at site 05 & -1.3746 & 0.5126 & -0.2776 \\
\hline $\mathrm{HgCl}_{2}$ at site 01 & -0.3929 & -0.0128 & -0.2843 \\
\hline $\mathrm{HgCl}_{2}$ at site 02 & -0.4399 & -0.0127 & -0.3272 \\
\hline $\mathrm{HgCl}_{2}$ at site 03 & -1.3401 & 0.2300 & -0.2531 \\
\hline $\mathrm{HgCl}_{2}$ at site 04 & -1.1333 & 0.1618 & -0.2669 \\
\hline $\mathrm{HgCl}_{2}$ at site 05 & -1.2707 & 0.4200 & -0.2090 \\
\hline $\mathrm{Hg}^{0}$ at site 01 & -1.1734 & -0.0002 & -0.1282 \\
\hline $\mathrm{Hg}^{0}$ at site 02 & -0.3097 & -0.0001 & -0.1908 \\
\hline $\mathrm{HgClBr}$ at site 01 & -0.2984 & -0.0089 & -0.1746 \\
\hline $\mathrm{HgClBr}(\mathrm{R})$ at site 01 & -0.2601 & -0.0099 & -0.1694 \\
\hline $\mathrm{HgClBr}$ at site 02 & -0.3771 & -0.0099 & -0.2366 \\
\hline $\mathrm{HgClBr}(\mathrm{R})$ at site 02 & -0.7273 & 0.0461 & -0.3183 \\
\hline $\mathrm{HgClBr}$ at site 03 & -1.3535 & 0.2476 & -0.2344 \\
\hline $\mathrm{HgClBr}(\mathrm{R})$ at site 03 & -1.3633 & 0.2450 & -0.2523 \\
\hline $\mathrm{HgClBr}$ at site 04 & -1.2283 & 0.2754 & -0.2382 \\
\hline $\mathrm{HgClBr}(\mathrm{R})$ at site 04 & -4.3254 & 2.8075 & -0.1013 \\
\hline \multicolumn{4}{|l|}{ Ice- Ih $^{3}$} \\
\hline $\mathrm{HgO}$ at site 01 & -2.7425 & -0.0431 & 0.4389 \\
\hline $\mathrm{HgBr}_{2}$ at site 01 & -0.2839 & -0.0082 & -0.0279 \\
\hline $\mathrm{HgBr}_{2}$ at site 02 & -0.7769 & 0.0352 & 0.0215 \\
\hline $\mathrm{HgCl}_{2}$ at site 01 & -0.1906 & -0.0133 & -0.0271 \\
\hline $\mathrm{HgCl}_{2}$ at site 02 & -0.5781 & 0.0198 & 0.0097 \\
\hline $\mathrm{Hg}^{0}$ at site 01 & -2.2381 & 0.0000 & 1.2538 \\
\hline $\mathrm{HgClBr}$ at site 01 & -0.2359 & -0.0007 & -0.0428 \\
\hline $\mathrm{HgClBr}(\mathrm{R})$ at site 01 & -0.1670 & -0.0004 & -0.0429 \\
\hline $\mathrm{HgClBr}$ at site 02 & -0.6793 & 0.0337 & 0.0010 \\
\hline $\mathrm{HgClBr}(\mathrm{R})$ at site 02 & -0.6473 & 0.0483 & -0.0286 \\
\hline \multicolumn{4}{|l|}{ Halite } \\
\hline $\mathrm{HgO}$ at site 01 & -1.3392 & -0.0409 & -0.0654 \\
\hline $\mathrm{HgO}(\mathrm{R})$ at site 01 & -1.6920 & 1.3144 & 0.4622 \\
\hline $\mathrm{HgO}$ at site 02 & -1.2257 & -0.0471 & 0.0596 \\
\hline $\mathrm{HgBr}_{2}$ at site 01 & -0.6523 & -0.0072 & -0.1017 \\
\hline $\mathrm{HgBr}_{2}$ at site 02 & -1.3099 & 0.0270 & -0.0492 \\
\hline $\mathrm{HgCl}_{2}$ at site 01 & -0.6015 & -0.0126 & -0.0883 \\
\hline $\mathrm{HgCl}_{2}$ at site 02 & -1.2190 & 0.0151 & -0.0200 \\
\hline $\mathrm{Hg}^{0}$ at site 01 & -0.5850 & 0.0000 & -0.0903 \\
\hline $\mathrm{HgClBr}$ at site 01 & -0.6156 & -0.0092 & -0.0914 \\
\hline $\mathrm{HgClBr}(\mathrm{R})$ at site 01 & -0.6670 & -0.0101 & -0.0922 \\
\hline $\mathrm{HgClBr}$ at site 02 & -1.2864 & 0.0221 & -0.0312 \\
\hline \multicolumn{4}{|l|}{ Illite } \\
\hline $\mathrm{HgO}$ at site 01 & -0.7580 & -0.0303 & -0.0374 \\
\hline $\mathrm{HgO}$ at site 02 & -2.7811 & -0.0368 & 0.2363 \\
\hline $\mathrm{HgO}$ at site 03 & -2.4241 & -0.0338 & 0.3532 \\
\hline $\mathrm{HgBr}_{2}$ at site 01 & -0.4654 & -0.0083 & -0.1244 \\
\hline $\mathrm{HgBr}_{2}$ at site 02 & -0.4819 & -0.0072 & -0.1033 \\
\hline $\mathrm{HgBr}_{2}$ at site 03 & -1.5358 & 0.8989 & 0.1841 \\
\hline $\mathrm{HgBr}_{2}$ at site 04 & -0.9447 & 0.1275 & -0.0940 \\
\hline $\mathrm{HgCl}_{2}$ at site 01 & -0.3195 & -0.0127 & -0.1309 \\
\hline $\mathrm{HgCl}_{2}$ at site 02 & -0.3720 & -0.0117 & -0.1114 \\
\hline $\mathrm{HgCl}_{2}$ at site 03 & -1.5267 & 0.8667 & 0.1673 \\
\hline $\mathrm{HgCl}_{2}$ at site 04 & -0.9193 & 0.1077 & -0.1021 \\
\hline $\mathrm{Hg}^{0}$ at site 01 & -0.6346 & 0.0000 & -0.1017 \\
\hline $\mathrm{HgClBr}$ at site 01 & -0.3230 & -0.0094 & -0.1302 \\
\hline $\mathrm{HgClBr}(\mathrm{R})$ at site 01 & -0.2869 & -0.0098 & -0.1321 \\
\hline
\end{tabular}




$\begin{array}{cccc}\mathrm{HgClBr} \text { at site } 02 & -0.3789 & -0.0114 & -0.1127 \\ \mathrm{HgClBr}(\mathrm{R}) \text { at site } 02 & -0.5258 & -0.0087 & -0.1118 \\ \mathrm{HgClBr} \text { at site } 03 & -1.5758 & 0.8376 & 0.1534 \\ \mathrm{HgClBr}(\mathrm{R}) \text { at site } 03 & -1.5144 & 0.8134 & 0.1281 \\ \mathrm{HgClBr} \text { at site } 04 & -0.9412 & 0.1600 & -0.0828 \\ \mathrm{HgClBr}(\mathrm{R}) \text { at site } 04 & -0.9330 & 0.1521 & -0.0870\end{array}$

${ }^{(1)}$ Binding energy that indicates energy difference between the final and initial states of adsorption $\left(E_{\mathrm{B}}=E_{\mathrm{Hg}-\mathrm{Surf}}-E_{\mathrm{Hg}}^{0}-\right.$ $E_{\text {Surf; }}^{0}$ Figure 1).

${ }^{(2)}$ Energy difference of the adsorbate driven by either a change in molecular configuration or molecular dissociation (Inconsistency in the $\mathrm{Hg}^{0}$ results is due to using a finite number of basis sets, but negligible).

${ }^{(3)}$ Energy difference of the adsorbent associated with its structural change.

${ }^{(4)} \mathrm{R}$ denotes the flipped orientation of the $\mathrm{Hg}^{\mathrm{II}}$ compounds.

Table S4. Calculated binding energy $\left(E_{\mathrm{B}} ; \mathrm{eV}\right)$ for $\mathrm{Hg}$ and $\mathrm{HgX}(\mathrm{HgBr}$ and $\mathrm{HgCl})$ formed by dissociative adsorption of $\mathrm{Hg}^{\mathrm{II}}$ on ice-Ih (e.g., Figs. 1a, 1b, 1c, 1e, and 1f), i.e., $E_{\mathrm{B}}(\mathrm{Hg})$ and $E_{\mathrm{B}}(\mathrm{HgX})$.

\begin{tabular}{|c|c|c|}
\hline Dissociative adsorption & $E_{\mathrm{B}}\left(\mathrm{Hg}^{\mathrm{II}}\right)$ & (1) $E_{\mathrm{B}}\left(\mathrm{Hg}^{0}\right)$ or $E_{\mathrm{B}}(\mathrm{HgX})$ \\
\hline \multicolumn{3}{|l|}{ Ice-Ih ${ }^{1}$} \\
\hline $\mathrm{HgCl}_{2}$ at site $02 \rightarrow \mathrm{Hg}^{0}$ & -5.2501 & -0.3468 \\
\hline $\mathrm{HgBr}_{2}$ at site $02 \rightarrow \mathrm{Hg}^{0}$ & -5.0205 & -0.2448 \\
\hline $\mathrm{HgO}$ at site $01 \rightarrow \mathrm{Hg}^{0}$ & -7.6604 & -0.1306 \\
\hline $\mathrm{HgO}$ at site $02 \rightarrow \mathrm{Hg}^{0}$ & -7.7001 & -0.0836 \\
\hline $\mathrm{HgClBr}$ at site $02 \rightarrow \mathrm{Hg}^{0}$ & -5.0604 & -0.2598 \\
\hline (2) $\mathrm{HgClBr}(\mathrm{R})$ at site $02 \rightarrow \mathrm{Hg}^{0}$ & -5.1203 & -0.2381 \\
\hline $\mathrm{HgCl}_{2}$ at site $01 \rightarrow \mathrm{HgCl}$ & -1.8149 & -0.7009 \\
\hline $\mathrm{HgBr}_{2}$ at site $01 \rightarrow \mathrm{HgBr}$ & -1.7213 & -0.6022 \\
\hline $\mathrm{HgClBr}$ at site $01 \rightarrow \mathrm{HgBr}$ & -1.8637 & -0.6797 \\
\hline $\mathrm{HgClBr}(\mathrm{R})$ at site $01 \rightarrow \mathrm{HgCl}$ & -1.6469 & -0.6601 \\
\hline \multicolumn{3}{|l|}{ Ice-Ih ${ }^{2}$} \\
\hline $\mathrm{HgO}$ at site $02 \rightarrow \mathrm{Hg}^{0}$ & -4.9529 & -0.1573 \\
\hline $\mathrm{HgBr}_{2}$ at site $04 \rightarrow \mathrm{HgBr}$ & -4.2849 & (3) -3.7074 \\
\hline $\mathrm{HgClBr}(\mathrm{R})$ at site $04 \rightarrow \mathrm{HgCl}$ & -4.3254 & (3) -3.7982 \\
\hline
\end{tabular}

${ }^{(1)}$ Binding energy $\left(E_{\mathrm{B}}\right)$ of $\mathrm{Hg}^{0}, \mathrm{HgCl}$, or $\mathrm{HgBr}$ formed by dissociative adsorption of $\mathrm{Hg}^{\mathrm{II}}$ compounds on the ice-Ih ${ }^{1}$ and ice- $\mathrm{Ih}^{2}$ surfaces.

${ }^{(2)} \mathrm{R}$ denotes the flipped orientation of $\mathrm{Hg}^{\mathrm{II}}$ compounds.

${ }^{(3)}$ Dissociated $\mathrm{HgBr}$ and $\mathrm{HgCl}$ form covalent-like bonds with unpaired $\mathrm{d}(\mathrm{O})$ atoms at proton defects. 


\section{SI4. $E_{B}$ convergence with respect to the vacuum space and the surface area}

Considering the computational efficiency, the surface models with the large vacuum space ( $\sim 40 \AA$ ) were used instead of applying the dipole correction. Figure S3 presents the convergence of $E_{\mathrm{B}}\left(\mathrm{HgBr}_{2}\right)$ on ice- $\mathrm{Ih}^{1}$ with varying the size of vacuum space $\left(L / L_{0} ; L_{0}=\sim 40 \AA\right.$ used in this study). The vacuum space of $\sim 40 \AA$ sufficiently reduce the dipole interaction of the highly ordered ice surface structure. $E_{\mathrm{B}}\left(\mathrm{HgBr}_{2}\right)$ is converged when $L / L_{0}>0.8$ within the order of $\sim 0.1 \mathrm{eV}$. In addition, when the dipole correction is applied to the case of $L / L_{0}=1.0, E_{\mathrm{B}}\left(\mathrm{HgBr}_{2}\right)$ changes only slightly within the order of $\sim 0.1 \mathrm{eV}$.

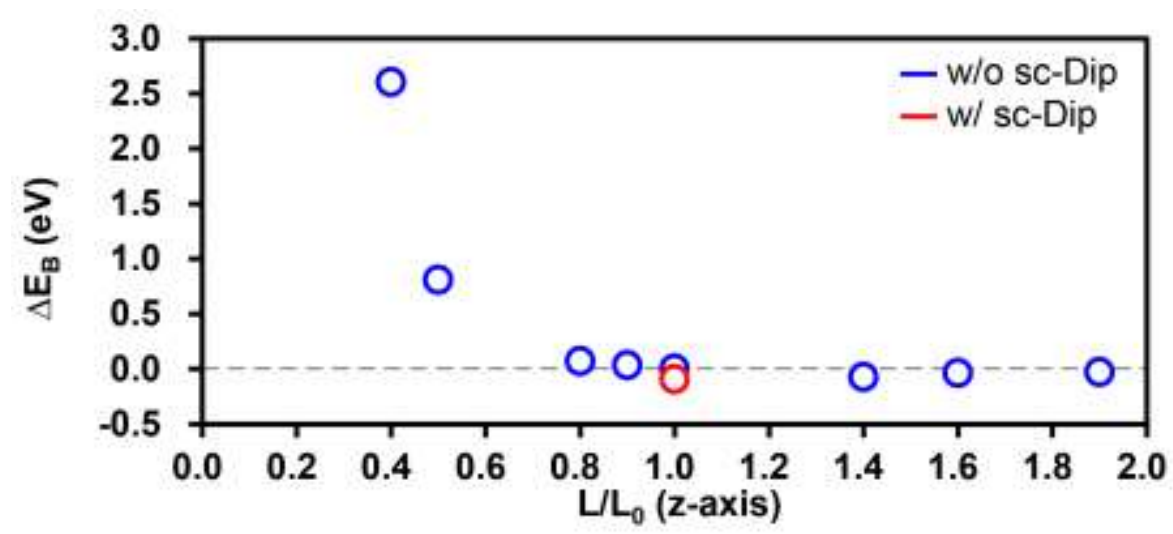

Figure S3. Variations in $E_{\mathrm{B}}\left(\mathrm{HgBr}_{2}\right)$ on ice- $\mathrm{Ih}^{1}$ with varying the size of vacuum space $\left(L / L_{0} ; L_{0}=\sim 40\right.$ $\AA$ ), where $\Delta E_{\mathrm{B}}=E_{\mathrm{B}}(L)-E_{\mathrm{B}}\left(L_{0}\right)$.

In addition, laterally periodic images can affect the adsorption behaviors of $\mathrm{Hg}^{\mathrm{II}}$ molecules on adsorbents. We used the large-area surface model, so that the periodically repeated $\mathrm{Hg}$ dihalides are sufficiently separated; $\sim 11.8 \AA$ and $\sim 18.6 \AA$ for each lateral direction. We further examined the convergence of $E_{\mathrm{B}}\left(\mathrm{HgBr}_{2}\right)$ on ice- $\mathrm{Ih}^{1}$ with respect to the surface area (Figure S4). The results in Fig. S4 show that further increases in the surface area did not cause significant changes in the calculated $E_{\mathrm{B}}$. Therefore, the large-area surface model used here would be sufficient to minimize the influence of the lateral interaction between the periodic images. According to the results in Figs. S3 and S4, the precision of calculated $E_{\mathrm{B}}$ values would be in the order of $\sim 0.1 \mathrm{eV}$. 


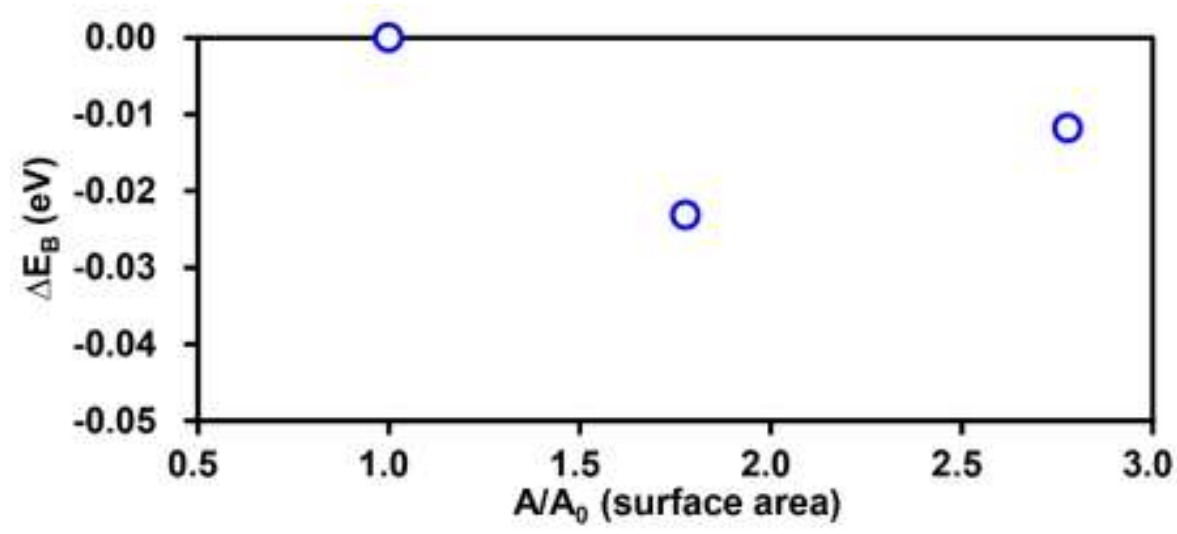

Figure S4. Variation in $E_{\mathrm{B}}\left(\mathrm{HgBr}_{2}\right)$ on ice- $\mathrm{Ih}^{1}$ with increasing the surface area $\left(A / A_{0} ; A_{0}=\sim 317.9 \AA^{2}\right)$, where $\Delta E_{\mathrm{B}}=E_{\mathrm{B}}(A)-E_{\mathrm{B}}\left(A_{0}\right)$. The number of $\mathrm{H}_{2} \mathrm{O}$ molecules on the uppermost bilayer increases from 36 to 100 with increasing $A / A_{0}$ from 1.0 to 2.8 .

\section{SI5. Calculation of vibrational energy of adsorbed $\mathrm{Hg}$}

The vibrational modes $\left(v_{\mathrm{j}}\right)$ of $\mathrm{Hg}$ adsorbed on ice-Ih were estimated by the finite displacement method. ${ }^{37}$ The step size of displacement for partial phonon calculations was set to 0.05 $\AA$ (convergence was tested with $0.01 \AA$ ). The zero-point energy $\left(E_{\mathrm{ZP}}\right)$ and vibrational energy $\left(E_{\mathrm{vib}}\right)$ were calculated as follows, ${ }^{38}$ where $h, k_{\mathrm{B}}$, and $T$ are the Planck constant, the Boltzmann constant, and the temperature, respectively:

$$
E_{\mathrm{vib}}(T)=\sum_{\mathrm{j}} \frac{1}{2} h v_{\mathrm{j}}+\sum_{\mathrm{j}} \frac{h v_{\mathrm{j}} \exp \left(-\frac{h v_{\mathrm{j}}}{k_{\mathrm{B}} T}\right)}{1-\exp \left(-\frac{h v_{\mathrm{j}}}{k_{\mathrm{B}} T}\right)}=E_{\mathrm{ZP}}+\sum_{\mathrm{j}} \frac{h v_{\mathrm{j}} \exp \left(-\frac{h v_{\mathrm{j}}}{k_{\mathrm{B}} T}\right)}{1-\exp \left(-\frac{h v_{\mathrm{j}}}{k_{\mathrm{B}} T}\right)}
$$

The pre-exponential factor of the Arrhenius expression for the desorption rate $(k)$ is the product of $k_{\mathrm{B}} T / h$ and $\exp \left[-\Delta E_{\mathrm{vib}} / k_{\mathrm{B}} T\right]$, where $\Delta E_{\mathrm{vib}}$ is the vibrational energy difference between initial and transition states $\left(E_{\mathrm{vib}}^{\mathrm{TS}}-E_{\mathrm{vib}}^{\mathrm{IS}}\right)$. It is often written as the attempt frequency of desorption process $\left(v_{0}=\right.$ $\prod_{\mathrm{i}}^{\mathrm{N}} v_{\mathrm{i}} / \prod_{\mathrm{j}}^{\mathrm{N}-1} v_{\mathrm{j}}$, where $v_{\mathrm{i}}$ and $v_{\mathrm{j}}$ indicate the vibrational modes at initial and transition states, respectively (see Ref. for details ${ }^{39}$ ). 
The desorption process would be accelerated by the thermally induced vibration $\left(E_{\mathrm{vib}}\right)$. Thus, the temperature dependences of normalized desorption rate $\left(k / v_{0}\right)$ and residence time $\left(\tau v_{0}\right)$ can be approximated as follows:

$$
k / v_{0} \approx \exp \left(-\frac{E_{\mathrm{A}}-E_{\mathrm{vib}}}{k_{\mathrm{B}} T}\right), \quad \tau v_{0} \approx \exp \left(\frac{E_{\mathrm{A}}-E_{\mathrm{vib}}}{k_{\mathrm{B}} T}\right)
$$

Here, $E_{\mathrm{A}}$ is the activation energy barrier for desorption, which refers to the energy required to separate the adsorbed $\mathrm{Hg}$ from the adsorbent, and then $E_{\mathrm{A}} \approx-E_{\mathrm{B}}$ (assuming simple dissociation). Although the phonon calculations and transition state searching are necessary to precisely determine the attempt frequency $\left(v_{0}\right)$, this semi-quantitative analysis can be used to assess the temperature dependence of desorption rate $(k)$ and residence time $(\tau)$ of atmospheric $\mathrm{Hg}$ adsorbed on the ice surfaces.

\section{SI6. Calculated $\boldsymbol{E}_{\text {vib values }}$}

The calculated vibrational energies $\left(E_{\mathrm{vib}}\right)$ and zero-point energy $\left(E_{\mathrm{ZP}}\right)$ for $\mathrm{Hg}^{0}$ and $\mathrm{HgBr}_{2}$ adsorbed on the ice- $\mathrm{Ih}^{2}$ surface, with corresponding kinetic parameters, are listed in Table S5 (details in Fig. 5).

Table S5. Calculated vibrational energy $\left(E_{\mathrm{vib}} ; \mathrm{eV}\right)$ and zero-point energy $\left(E_{\mathrm{ZP}} ; \mathrm{eV}\right)$ for $\mathrm{Hg}^{0}$ and $\mathrm{HgBr}_{2}$ adsorbed on the ice- $\mathrm{Ih}^{2}$ surface, with a normalized desorption rate $\left(k / v_{0}\right)$ and residence time $\left(\tau v_{0}\right)$ (see Fig. 5).

\begin{tabular}{ccccc}
\hline Temperature $(\mathbf{K})$ & $\boldsymbol{E}_{\mathbf{Z P}}$ & $\boldsymbol{E}_{\text {vib }}$ & $\boldsymbol{k} / \boldsymbol{v}_{\mathbf{0}}$ & $\boldsymbol{\tau} \boldsymbol{v}_{\mathbf{0}}$ \\
\hline $\mathbf{H g}^{\mathbf{0}}$ on ice- $\mathbf{I h}^{\mathbf{2}}$ & & & & \\
200 & 0.0157 & 0.0533 & $1.0250 \times 10^{-25}$ & $9.7565 \times 10^{24}$ \\
273 & 0.0157 & 0.0718 & $1.0794 \times 10^{-18}$ & $9.2646 \times 10^{17}$ \\
300 & 0.0157 & 0.0787 & $5.8295 \times 10^{-17}$ & $1.7154 \times 10^{16}$ \\
$\mathbf{H g B r}_{\mathbf{2}}$ on ice-Ih & & & & \\
200 & 0.0104 & 0.0525 & $4.3368 \times 10^{-34}$ & $2.3058 \times 10^{33}$ \\
273 & 0.0104 & 0.0712 & $7.9927 \times 10^{-25}$ & $1.2511 \times 10^{24}$ \\
300 & 0.0104 & 0.0781 & $1.5410 \times 10^{-22}$ & $6.4894 \times 10^{21}$ \\
\hline
\end{tabular}




\section{SI7. Calculation of UV-VIS absorption spectra}

The UV-VIS absorption spectra of the $\mathrm{Hg}^{\mathrm{II}}$-adsorbed ice were obtained via the DFT-based optical property calculations in CASTEP. In contrast to the $E_{\mathrm{B}}$ calculations, the ice cluster models were used for the UV-VIS calculations to magnify the characteristic absorption features stemming from the intermolecular interactions between $\mathrm{Hg}^{\mathrm{II}}$ and ice such as $\mathrm{Hg}-\mathrm{d}(\mathrm{O})$ and multiple $\mathrm{Br}-\mathrm{d}(\mathrm{H})$ at the uppermost layer. The molecular clusters used for the UV-VIS calculations were cleaved from the $\mathrm{Hg}^{\mathrm{II}}$-adsorbed surface structures used for the $E_{\mathrm{B}}$ calculations; the geometry optimizations were carried out with following tolerances: $2 \times 10^{-5} \mathrm{eV} /$ atom, $0.05 \mathrm{eV} / \AA, 0.1 \mathrm{GPa}$, and $0.002 \AA$ for total energy, maximum force, maximum stress, and maximum displacement, respectively. The coordinates of outermost $\mathrm{H}_{2} \mathrm{O}$ molecules of the ice clusters were constrained to preserve the ice-Ih surface configuration. The vacuum space above the uppermost $\mathrm{d}(\mathrm{H})$ atoms was $>\sim 35 \square$ sufficient to neglect dipole moments of the ice model; applying the dipole correction does not induce noticeable changes in the UV-VIS absorption cross section. Parameters for UV-VIS calculations are described in the manuscript (see Method). The relativistic effect on the calculated UV-VIS absorption spectra, particularly the spin-orbit effect, is discussed in the manuscript (see Fig. 4) and the Sec. 8 below.

\section{SI8. Relativistic effects on Hg compounds}

To improve the accuracy of core-level electronic structures and intra-molecular interactions of transition metals (e.g., Au in other studies and $\mathrm{Hg}$ this work), the relativistic effect is to be dealt with, which can correct the core-level orbital contraction and the indirect outer orbital expansion, thereby providing the more accurate effective charge and atomic radius of heavy elements. ${ }^{16,40}$ Thus, the relativistic corrections have been applied to systems containing heavy elements, where the scalar relativistic correction includes the relativistic mass and Darwin terms and the full relativistic correction additionally considers the spin-orbit coupling effect. ${ }^{41}$ The full relativistic treatment is usually implemented as following order: (1) applying the scalar relativistic correction in each SCF cycle and (2) adding the non-self-consistent second-order variational term for the spin-orbit coupling in the end of the SCF calculation. ${ }^{16,40}$

Whereas the spin-orbit coupling effect is usually important for heavy elements, previous studies showed that its contribution to $\mathrm{Hg}$ compounds, particularly for $\mathrm{HgO}$ and $\mathrm{HgBr}_{2}$, is 
insignificant. The spin-orbit coupling effect on the $\mathrm{Hg}$ atom causes the orbital splitting from $p$ and $d$ states into $5 p_{1 / 2}-5 p_{3 / 2}$ and $5 d_{3 / 2}-5 d_{5 / 2}$ states (see the previous study for details ${ }^{40}$ ). However, for $\mathrm{HgO}$ and $\mathrm{HgBr}_{2}$ molecules, the unpaired electrons causing the spin-orbital coupling are mostly located in oxygen/halogen atoms (for the low-lying molecular orbital state) or in the $\mathrm{Hg} 6 s$ state (for the higher molecular orbital state), thereby mitigating the spin-orbit coupling effect on the $\mathrm{HgO}$ and $\mathrm{HgBr}_{2}$ molecules. ${ }^{42-44}$ The previous studies using the post-Hartree-Fock methods revealed that the differences in vertical electronic excitation energies (i.e., corresponding to the results of electronic transition spectroscopy; e.g., UV-VIS) with/without the spin-orbit splitting are within the order of $0.01 \mathrm{eV}\left(\sim 0.1 \mathrm{eV}\right.$ for the relative energy level of molecular orbitals) for $\mathrm{HgBr}_{2}, \mathrm{HgO}$, and $\mathrm{HgS}$ (i.e., the valence isoelectronic molecule of $\mathrm{HgO}){ }^{42,45-47}$

Besides the relatively weak spin-orbit effect on $\mathrm{Hg}$ compounds, the benchmark calculations showed that the scalar relativistic correction could provide sufficiently converged and reliable DOS and X-ray absorption features; for instance, the spin-orbit coupling gives rise to almost negligible differences for $\mathrm{Au}$ and $\mathrm{Ag}$ (see details in user guides of WIEN2 $\mathrm{k}^{16}$ and CASTEP ${ }^{12}$ ). Therefore, the current UV-VIS calculations with the scalar relativistic correction may not accurately reveal detailed features but can assess the possibility of electronic transition under corresponding UV radiations (details in the manuscript; Fig. 4).

\section{SI9. Peak assignments for calculated UV-VIS spectra in Fig. 4}

In order to assign the characteristic absorption features stemming from the interactions of $\mathrm{Hg}-\mathrm{d}(\mathrm{O})$ and $\mathrm{Br}-\mathrm{d}(\mathrm{H})$, we examined changes in the UV-VIS spectra with increasing the distance $(d)$ between the $\mathrm{Hg}^{\mathrm{II}}$ molecules (adsorbate) and the ice clusters (adsorbent) without further geometry optimization. Figure S3 presents the calculated UV-VIS spectra for $\mathrm{Hg}$ on ice- $\mathrm{Ih}^{\mathrm{B}}\left(\mathrm{Hg} / \mathrm{ice}^{-\mathrm{Ih}^{\mathrm{B}}}\right)$, $\mathrm{HgBr}_{2} /$ ice- $^{\mathrm{B}}{ }^{\mathrm{B}}$, and $\mathrm{Br} \cdots \mathrm{Hg} \cdots \mathrm{Br} /$ ice- $\mathrm{Ih}^{\mathrm{A}}$ (dissociatively adsorbed $\mathrm{HgBr}_{2}$ on ice- $\mathrm{Ih}^{\mathrm{A}}$ ) with varying the distance of either $\mathrm{Hg}-\mathrm{d}(\mathrm{O})$ or $\mathrm{Br}-\mathrm{d}(\mathrm{H})\left(d / d_{0}\right)$ from 1.0 to 5.0, where $d_{0}$ indicates the $d$ when the adsorbate is adsorbed (Figs. $4 b-4 d$ ).

(1) Hg-d(O) peak of $\mathrm{Hg} /$ ice-Ih ${ }^{\mathrm{B}}$ (Fig. S3a): The $\mathrm{Hg}$ peaks at $\sim 120$ and $\sim 180 \mathrm{~nm}$ (when $\left.d / d_{0}=5.0\right)$ become small bimodal peaks with decreasing $d / d_{0}$. Then, new absorption features, which emerge at 
$\sim 150$ and $\sim 300-350 \mathrm{~nm}$ when $\mathrm{Hg}$ is adsorbed on ice through the $\mathrm{Hg}-\mathrm{d}(\mathrm{O})$ binding $\left(d / d_{0}=1.0\right)$, are assigned to the $\mathrm{Hg}-\mathrm{d}(\mathrm{O})$ peaks.

(2) $\mathrm{Hg}-\mathrm{d}(\mathrm{O})$ peak of $\mathrm{HgBr}_{2} /$ ice- $\mathrm{Ih}^{\mathrm{B}}$ (Fig. S3a): The peak of $\mathrm{HgBr}_{2}$ appeared when $d / d_{0}=5.0$ (assigned to $\mathrm{Hg}$ and $\mathrm{Hg}-\mathrm{Br}$ according to the result of $\mathrm{HgBr}_{2}$ in Fig. 4) shifts to shorter wavelength regions with decreasing $d / d_{0}$. The characteristic feature at $\sim 300 \mathrm{~nm}$, appeared when $\mathrm{HgBr}_{2}$ is adsorbed on ice through the $\mathrm{Hg}-\mathrm{d}(\mathrm{O})$ binding $\left(d / d_{0}=1.0\right)$, are assigned to the $\mathrm{Hg}-\mathrm{d}(\mathrm{O})$ peak. The $\mathrm{Hg}$ $\mathrm{d}(\mathrm{O})$ feature at $\sim 150 \mathrm{~nm}$ observed in the results of $\mathrm{Hg} / \mathrm{ice}^{-\mathrm{Ih}^{\mathrm{B}}}$ does not appear clearly. The broad feature at $\sim 100-150 \mathrm{~nm}$ might be attributed to the presence of $\mathrm{Br}$ atoms because it does not appear in the result of $\mathrm{Hg} /$ ice- $^{\mathrm{B}} \mathrm{B}^{\mathrm{B}}$; but the evidence of $\mathrm{Br}-\mathrm{d}(\mathrm{H})$ interaction is unclear even with decreasing $d / d_{0}$.

(3) $\mathrm{Br}-\mathrm{d}(\mathrm{H})$ peak of $\mathrm{Br} \cdots \mathrm{Hg} \cdots \mathrm{Br} /$ ice-Ih $^{\mathrm{A}}$ (Fig. S3b): In order to identify the $\mathrm{Hg}$ and $\mathrm{Br}-\mathrm{d}(\mathrm{H})$ peaks, we calculated each spectrum for (1) $\mathrm{Hg}$ /ice- $\mathrm{Ih}^{\mathrm{A}}$ and (2) $\mathrm{Br} \cdots \mathrm{Br} / \mathrm{ice}-\mathrm{Ih}^{\mathrm{A}}$ with increasing $d / d_{0}$ as presented in the bottom and the middle panels of Fig. R3b, respectively. The results of $\mathrm{Hg} / \mathrm{ice}-\mathrm{Ih}^{\mathrm{A}}$ show apparent changes at $\sim 125$ and $\sim 185 \mathrm{~nm}$ with decreasing $d / d_{0}$, thus assigned to the Hg peaks. In the results of $\mathrm{Br} \cdots \mathrm{Br} / \mathrm{ice}^{\mathrm{i}} \mathrm{Ih}^{\mathrm{A}}$, a noticeable increase in the peak intensity is observed at $\sim 110-140 \mathrm{~nm}$ when the $\mathrm{Br}$ atoms are adsorbed on nearby $\mathrm{d}(\mathrm{H})$ atoms of ice- $\mathrm{Ih}^{\mathrm{A}}\left(d / d_{0}=1.0\right)$; it is thus assigned to the $\operatorname{Br}-\mathrm{d}(\mathrm{H})$ peak. 

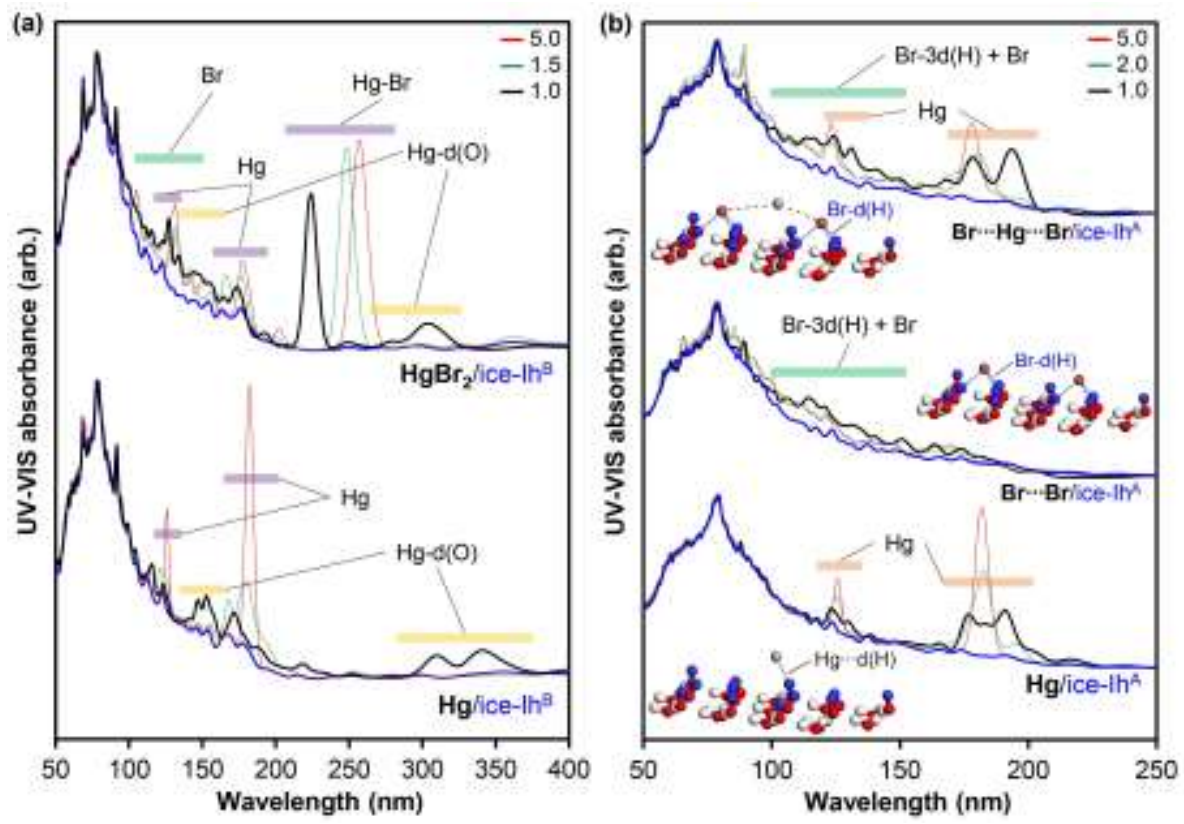

Figure S5. Calculated UV-VIS spectra for $\mathrm{Hg}^{\mathrm{II}}$ molecules on ice clusters with varying the distance $\left(d / d_{0}\right)$ between the $\mathrm{Hg}^{\mathrm{II}}$ molecules and the ice clusters from 1.0 to 5.0. $d_{0}$ represents the $d$ when the adsorbate is adsorbed. (a) $\mathrm{Hg}$ and $\mathrm{HgBr}_{2}$ on ice- $\mathrm{Ih}^{\mathrm{B}}$ and (b) $\mathrm{HgBr}_{2}$ on ice- $\mathrm{Ih}^{\mathrm{A}}$. Here, (1) for $\mathrm{Hg}$ $\mathrm{d}(\mathrm{O})$ in $\mathrm{Hg} /$ ice- $\mathrm{Ih}^{\mathrm{B}}, d_{0}=2.196 \AA$, (2) for $\mathrm{Hg}$-d(O) in $\mathrm{HgBr}_{2} / \mathrm{ice}^{-\mathrm{Ih}^{\mathrm{B}}}, d_{0}=2.272 \AA$, and (3) for Br$\mathrm{d}(\mathrm{H})$ and $\mathrm{Hg} \cdots \mathrm{d}(\mathrm{H})$ in $\mathrm{Br} \cdots \mathrm{Hg} \cdots \mathrm{Br} /$ ice- $^{\mathrm{A}} \mathrm{Ih}^{\mathrm{A}}, d_{0}=2.244$ and $2.604 \AA$, respectively. The UV-VIS spectra of the ice clusters are shown for comparison (blue solid; ice-- $\mathrm{Ih}^{\mathrm{A}}$ and ice- $\mathrm{Ih}^{\mathrm{B}}$ by removing adsorbates without further geometry optimization). 


\section{References}

1. Lee, B. H.; Lee, S. K., Effect of lattice topology on the adsorption of benzyl alcohol on kaolinite surfaces: Quantum chemical calculations of geometry optimization, binding energy, and NMR chemical shielding. American Mineralogist 2009, 94 (10), 1392-1404.

2. Kwon, K. D.; Refson, K.; Sposito, G., Surface complexation of $\mathrm{Pb}(\mathrm{II})$ by hexagonal birnessite nanoparticles. Geochim. Cosmochim. Acta 2010, 74 (23), 6731-6740.

3. Kwon, K. D.; Refson, K.; Sposito, G., Zinc surface complexes on birnessite: A density functional theory study. Geochim. Cosmochim. Acta 2009, 73 (5), 1273-1284.

4. Son, S.; Li, W.; Lee, J.-Y.; Kwon, K. D., On the coordination of $\mathrm{Mg}^{2+}$ in aragonite: Ab-initio absorption spectroscopy and isotope fractionation study. Geochim. Cosmochim. Acta 2020, 286, 324-335.

5. Kwon, K. D.; Sposito, G., Dirac's dream: Understanding metal sorption by geomedia using density functional theory. Chem. Geol. 2017, 464, 4-13.

6. Lee, S. K.; Kim, Y.-H.; Yi, Y. S.; Chow, P.; Xiao, Y.; Ji, C.; Shen, G., Oxygen quadclusters in $\mathrm{SiO}_{2}$ glass above megabar pressures up to $160 \mathrm{GPa}$ revealed by x-ray Raman scattering. Phys. Rev. Lett. 2019, 123 (23), 235701.

7. Kim, Y.-H.; Yi, Y. S.; Kim, H.-I.; Chow, P.; Xiao, Y.; Shen, G.; Lee, S. K., Structural transitions in $\mathrm{MgSiO}_{3}$ glasses and melts at the core-mantle boundary observed via inelastic X-ray scattering. Geophysical Research Letters 2019, 46 (n/a).

8. Coak, M. J.; Kim, Y.-H.; Yi, Y. S.; Son, S.; Lee, S. K.; Park, J.-G., Electronic and vibrational properties of the two-dimensional Mott insulator $\mathrm{V}_{0.9} \mathrm{PS}_{3}$ under pressure. Phys. Rev. B 2019, 100 (3), 035120.

9. Parq, J. H.; Lee, S. K.; Lee, S. M.; Yu, J., Ab Initio study of elastic properties of high-pressure polymorphs of $\mathrm{CO}_{2}$ phases II and V. J. Phys. Chem. C 2016, 120 (40), 23152-23164.

10. Yi, Y. S.; Lee, S. K., Atomistic origins of pressure-induced changes in the $\mathrm{O} K$-edge $\mathrm{X}$-ray Raman scattering features of $\mathrm{SiO}_{2}$ and $\mathrm{MgSiO}_{3}$ polymorphs: Insights from ab initio calculations. Phys. Rev. B 2016, 94 (9), 094110.

11. Yi, Y. S.; Lee, S. K., Pressure-induced changes in local electronic structures of $\mathrm{SiO}_{2}$ and $\mathrm{MgSiO}_{3}$ polymorphs: Insights from ab initio calculations of $\mathrm{O} K$-edge energy-loss near-edge structure spectroscopy. American Mineralogist 2012, 97 (5-6), 897-909.

12. Clark, S. J.; Segall, M. D.; Pickard, C. J.; Hasnip, P. J.; Probert, M. I. J.; Refson, K.; Payne, M. C., First principles methods using CASTEP. Z. Kristall. 2005, 220 (5/6), 567-570.

13. Perdew, J. P.; Burke, K.; Ernzerhof, M., Generalized gradient approximation made simple. Phys. Rev. Lett. 1996, 77 (18), 3865-3868.

14. Tkatchenko, A.; Scheffler, M., Accurate molecular van der Waals interactions from ground-state electron density and free-atom reference data. Phys. Rev. Lett. 2009, 102 (7), 073005.

15. Hébert, C., Practical aspects of running the WIEN2k code for electron spectroscopy. Micron 2007, $38(1), 12-28$. 
16. Blaha, P.; Schwarz, K.; Tran, F.; Laskowski, R.; Madsen, G. K. H.; Marks, L. D., WIEN2k: An APW+lo program for calculating the properties of solids. Journal of Chemical Physics 2020, 152 (7), 074101.

17. Han, C.; Li, T.; Zhang, W.; Zhang, H.; Zhao, S.; Ao, Y.; Wei, D.; Shen, Y., Density functional theory study on the surface properties and floatability of hemimorphite and smithsonite. Minerals 2018, 8 (12), 542 .

18. Zhang, K.; Zhang, P.; Wang, Z.-R.; Zhu, X.-L.; Lu, Y.-B.; Guan, C.-B.; Li, Y., DFT simulations of the vibrational spectrum and hydrogen bonds of ice XIV. Molecules 2018, 23 (7), 1781.

19. Zhang, P.; Wang, Z.; Lu, Y.-B.; Ding, Z.-W., The normal modes of lattice vibrations of ice XI. Sci. Rep. 2016, 6 (1), 29273.

20. Tse, J. S., Ab initio molecular dynamics with density functional theory. Annu. Rev. Phys. Chem. 2002, 53 (1), 249-290.

21. Schwarz, K., DFT calculations of solids with LAPW and WIEN2k. J. Solid State Chem. 2003, $176(2), 319-328$.

22. Marx, D., Hutter, J., Ab initio molecular dynamics: Theory and implementation. In Modern Methods and Algorithms of Quantum Chemistry, Grotendorst, J., Ed. NIC: FZ Julich, 2000; Vol. 1, pp 301-449.

23. Kwon, K. D.; Refson, K.; Sposito, G., Transition metal incorporation into mackinawite (tetragonal FeS) $\dagger$. American Mineralogist 2015, 100 (7), 1509-1517.

24. Gillan, M. J.; Alfe, D.; Michaelides, A., Perspective: how good is DFT for water? J. Chem. Phys. 2016, 144 (13), 130901.

25. Hammer, B.; Hansen, L. B.; Nørskov, J. K., Improved adsorption energetics within densityfunctional theory using revised Perdew-Burke-Ernzerhof functionals. Phys. Rev. B 1999, 59 (11), 7413-7421.

26. Buch, V.; Groenzin, H.; Li, I.; Shultz, M. J.; Tosatti, E., Proton order in the ice crystal surface. PNAS 2008, 105 (16), 5969-74.

27. Buch, V.; Milet, A.; Vacha, R.; Jungwirth, P.; Devlin, J. P., Water surface is acidic. PNAS 2007, 104 (18), 7342-7.

28. Jun, S.; Lee, J. H.; Kim, J.; Kim, J.; Kim, K. H.; Kong, Q.; Kim, T. K.; Lo Russo, M.; Wulff, M.; Ihee, $\mathrm{H}$., Photochemistry of $\mathrm{HgBr}_{2}$ in methanol investigated using time-resolved X-ray liquidography. Phys. Chem. Chem. Phys. 2010, 12 (37), 11536-11547.

29. Vanderbilt, D., Soft self-consistent pseudopotentials in a generalized eigenvalue formalism. Phys. Rev. B 1990, 41 (11), 7892-7895.

30. de Macedo, L. G. M.; Oliveira, C. A.; Gomes, J. S.; Alves, C. N.; de Souza, A. R.; Pimentel, A. S.; Gargano, R., Fully relativistic 4-components DFT investigation on bonding and dissociation energy of HgO. Journal of Computational and Theoretical Nanoscience 2011, 8 (1), 38-42.

31. McCulloch, D. G.; Lau, D. W. M.; Nicholls, R. J.; Perkins, J. M., The near edge structure of cubic boron nitride. Micron 2012, 43 (1), 43-48. 
32. Schreiber, M.; Silva-Junior, M. R.; Sauer, S. P. A.; Thiel, W., Benchmarks for electronically excited states: CASPT2, CC2, CCSD, and CC3. Journal of Chemical Physics 2008, 128 (13), 134110.

33. Arcisauskaite, V.; Knecht, S.; Sauer, S. P. A.; Hemmingsen, L., Electric field gradients in Hg compounds: Molecular orbital (MO) analysis and comparison of 4-component and 2-component (ZORA) methods. Phys. Chem. Chem. Phys. 2012, 14 (46), 16070-16079.

34. Hofer, T. S.; Randolf, B. R.; Rode, B. M., The hydration of the mercury(I)-dimer - A quantum mechanical charge field molecular dynamics study. Chem. Phys. 2008, 349 (1), 210-218.

35. Rode, B. M.; Hofer, T. S.; Randolf, B. R.; Schwenk, C. F.; Xenides, D.; Vchirawongkwin, V., Ab initio quantum mechanical charge field $(\mathrm{QMCF})$ molecular dynamics: a $\mathrm{QM} / \mathrm{MM}-\mathrm{MD}$ procedure for accurate simulations of ions and complexes. Theor. Chem. Acc. 2006, 115 (2), 77-85.

36. Yi, Y. S.; Han, Y.; Lee, S. K.; Hur, S. D., Atomistic view of mercury cycling in polar snowpacks: Probing the role of $\mathrm{Hg}^{2+}$ adsorption using ab initio calculations. Minerals 2019, 9 (8), 459.

37. Sternik, M.; Parlinski, K., Free-energy calculations for the cubic $\mathrm{ZrO}_{2}$ crystal as an example of a system with a soft mode. J. Chem. Phys. 2005, 123 (20), 204708.

38. Rasti, S.; Meyer, J., Importance of zero-point energy for crystalline ice phases: a comparison of force fields and density functional theory. J. Chem. Phys. 2019, 150 (23), 234504.

39. Koettgen, J.; Zacherle, T.; Grieshammer, S.; Martin, M., Ab initio calculation of the attempt frequency of oxygen diffusion in pure and samarium doped ceria. Phys. Chem. Chem. Phys. 2017, 19 (15), 9957-9973.

40. Huhn, W. P.; Blum, V., One-hundred-three compound band-structure benchmark of post-selfconsistent spin-orbit coupling treatments in density functional theory. Phys. Rev. Mater. 2017, 1 (3), 033803.

41. Koelling, D. D.; Harmon, B. N., A technique for relativistic spin-polarised calculations. J. Phys. C: Solid State Phys. 1977, 10 (16), 3107-3114.

42. Shepler, B. C.; Peterson, K. A., Mercury monoxide: A systematic investigation of its ground electronic state. Journal of Physical Chemistry A 2003, 107 (11), 1783-1787.

43. Wadt, W. R., The electronic structure of $\mathrm{HgCl}_{2}$ and $\mathrm{HgBr}_{2}$ and its relationship to photodissociation. Journal of Chemical Physics 1980, 72 (4), 2469-2478.

44. Filatov, M.; Cremer, D., Revision of the dissociation energies of mercury chalcogenides Unusual types of mercury bonding. ChemPhysChem 2004, 5 (10), 1547-1557.

45. Sitkiewicz, S. P.; Rivero, D.; Oliva-Enrich, J. M.; Saiz-Lopez, A.; Roca-Sanjuan, D., Ab initio quantum-chemical computations of the absorption cross sections of $\mathrm{HgX}_{2}$ and $\mathrm{HgXY}(\mathrm{X}, \mathrm{Y}=\mathrm{Cl}$, $\mathrm{Br}$, and I): molecules of interest in the Earth's atmosphere. Phys. Chem. Chem. Phys. 2019, 21 (1), 455-467.

46. Cressiot, C.; Guitou, M.; Mitrushchenkov, A.; Chambaud, G., Stability of the HgS molecule and spectroscopy of its low lying electronic states. Mol. Phys. 2007, 105 (9), 1207-1216. 
47. Tossell, J. A., Calculation of the Energetics for the Oligomerization of Gas Phase $\mathrm{HgO}$ and $\mathrm{HgS}$ and for the Solvolysis of Crystalline $\mathrm{HgO}$ and $\mathrm{HgS}$. Journal of Physical Chemistry A 2006, 110 (7), 2571-2578. 